\title{
Kardeş Durumu ve Mutluluk: Çanakkale'de Lise Öğrencileri Üzerine Bir Araştırma
}

\section{Ümit DEMIR $^{1}$}

$\ddot{O} z$

Mutluluk çok eskiden beri merak edilen bir konudur. Mutluluğun tanımı ve mutluluğa nasıl ulaşıla-bileceği çok eski dönemlerden beri sorgulanmaktadır. Mutluluğun temelinde sosyal iletișim ve etkileşim düzeyinin olduğu belirtilmektedir. Kişilerin en temel etkileşim ve iletişim alanları aileleridir. Bu çalışmada, lise öğrencilerinin kardeş durumuna (kardeş sayısı, cinsiyeti, yaş düzeyi) göre mutluluk düzeylerinin farklılaşma durumu araştırılmıştır. Araştırmanın örneklemini, Çanakkale merkez ilçesinde bir ortaöğretim kurumunda öğrenimlerine devam etmekte olan 489 öğrenci oluşturmaktadır. Araştırma kapsamında Hills ve Argyle tarafından geliştirilmiş ve Doğan ve Sapmaz (2012) tarafın-dan Türkçeye uyarlaması gerçekleştirilen “Oxford Mutluluk Ölçeği” kullanılmıştır. Ölçeğin iç tutarlılığını belirleme amacıyla yapılan analizde Cronbach alfa güvenilirlik katsayısı 0,76 olarak hesaplanmıştır. Verilerin çözümlenmesinde betimsel istatistik çözümleme yöntemlerinden yararlanılarak SPSS istatistik programı kullanılmıştır. Araştırma sonucunda, kardeş sayısına göre mutluluk puanları arasında anlamlı bir farklılık görülmezken, kardeş cinsiyet durumu ve yaş durumuna göre ise anlamlı farklılık saptanmıştır. Katılımcılardan kız kardeşi olanların ve diğer kardeşler-ine kıyasla küçük olanların diğerlerine kıyasla çok daha mutlu oldukları bulunmuştur.

Anabtar Kelimeler: Mutluluk, Kardeş, Aile

\section{Siblings' Position and Happiness: A Study of High School Students in Çanakkale}

\begin{abstract}
Happiness has been the theme for curiosity for a long time. The definition of happiness and how to achieve it have been questioned since ancient times. It has been stated that social communication and interaction level is the basis of happiness. People's main areas of interaction and communication are their families. The status of differentiation of levels of happiness depending on the status of the sibling (number of brothers and sisters, gender, age level) of high school students was studied in this research. The research based on the analyses of 489 students who continue their education at a secondary school of Canakkale. Within the scope of the re-search, the Oxford Happiness Scale which was developed by Hills and Argyle and adapted to Turkish by Doğan and Sapmaz (2012) was applied. For internal consistency of the scale, Cronbach alpha reliability coefficient was calculated as 0.76. SPSS statistics program and descriptive statistical analysis were used to analyze the data. The result of the research does not show significant difference between in scores according to a number of siblings but there was significant difference between happiness scores according to siblings' gender and siblings' age. It was found that participants having sisters and younger than their siblings were found happier while the study was carried out.
\end{abstract}

Key Words: Happiness, Sibling, Family

Atıf İçin / Please Cite As:

Demir, Ü. (2020). Kardeş durumu ve mutluluk: Çanakkale'de lise öğrencileri üzerine bir araştırma. Manas Sosyal Arastirmalar Dergisi, 9(2), 798-808.

Geliş Tarihi / Received Date: 12.04.2019

Kabul Tarihi / Accepted Date: 14.05.2019

\footnotetext{
${ }^{1}$ Dr. Öğr. Üyesi - Çanakkale Onsekiz Mart Üniversitesi Çanakkale Teknik Bilimler MYO, umitdemir@comu.edu.tr ORCID: 0000-0003-4899-4895
} 


\section{Giriş}

Mutluluk ve mutluluğun kaynağını araştırmaya duyulan merak çok eski tarihlerden beri süregelmektedir. Mutluluğun tanımı ve mutluluğu elde etme yolları Aristo'dan beri düşünülmektedir. Bu düşüncelerin ilk örnekleri Aristoteles'in mutluluk hakkındaki düşünceleridir. Aristotales'e göre, kadınlar ve erkekler yaşamlarında her şeyden çok mutluğu isterler. Sokrates'in ana problemi, "nasıl yaşayacağım?" olmuş-tur. Sokrates'ten yaklaşı 130 yil sonra ortaya çıan Stoa Okulu'na göre, insanın yaşamının amacını ve anlamını kavrayabilme çabası çok büyük önem arz etmektedir. Sonuç olarak, Aristo'dan itibaren yaklaşık 2000 yıldır insanlık yaşamının amacı ve mutluluk kavramı tartışılmaktadır (Büyükdüvenci, 1993, s. 41-45). Benzer şekilde, geçmiş yıllarda, psikologlarda, sağlıklı davranışlar yerine sağlıksız davranışlarla ve bireyin duygularından çok bireyin düşünceleri ile ilgilenmişlerdir. Bu düşünceye karşı olarak Seligman ve arkadaşlarının başlatmış olduğu, "Başarılı bireyin başarılı olmasını etkile-yen etmenler nelerdir?", "İyi yaşam nedir?" veya "Yaşamda başarılı ve mutlu olan bireylerin sahip oldukları nitelikler nelerdir?" gibi sorular üzerinde yoğunlaşarak, "psikolojik iyi olma" terimini daha öne çıkarmışlardır (Akın, 2008, s. 724). Günümüzde bu nedenle mutluluk ve iyi olma ifadeleri birbirleri yerine çok sık kullanılabilmektedir.

İyi oluş kavramı, psikolojide genel ruh sağlığını ifade eden kavram olarak kullanılmaktadır. Ruh sağlığı ile ilgili yapılan araştırmalar yakın bir geçmişe kadar genel-de, ruhsal sağlıklı olmayı, depresyon ve stres gibi diğer psikolojik olumsuz belirtilerin bulunmama durumu olarak görerek bu bakış açısından olaya yaklaşmışlardır. Bu yaklaşım biçimi, iyilik hali, iyi oluşu ve diğer tanımları açıklamada yetersiz kalmaktadır (Tanhan, 2007, s. 76). Dünya Sağllk Örgütü (WHO) sağllklı olmayı, "sadece sakatllğın ve hastaliğın bulunmaması olarak değil; ruhsal, sosyal ve bedensel yönlerden tam bir iyi oluş durumu" olarak belirtmektedir (Özen, 2010, s. 48). Bu nedenle günümüzde, ruhsal sağllğı, psikolojik sorunların olmamasına ek olarak, olumlu psikolojik hale sahip olunmasının, kendini iyi hissetmenin ve ayrica durumlara ve olaylara olumlu bakış açısına sahip olmanın önemini vurgulayacak şekilde belirtilmektedir. İnsanoğlu, her şeyden çok mutluluk isteği ile doludur. Mutlu olma talebi ve gayesi, insanların doğasında vardır. Ayrıca mutlu ve mutsuz insanların davranışları birbirlerine göre farklılık gösterebilmektedir.

Mutlu insanların yaşam olaylarını yorumlama, değerlendirme ve tepkide bulunma biçimleri daha az mutlu olan insanlardan da farklık göstermektedir (Ünüvar, Çalışandemir, Tagay ve Amini, 2015, s. 2). Yapılan araştırmalar mutlu insanlarda psiko-lojik rahatsızlıklara daha az rastlandığını göstermektedir (Lu, 1995; Lyubomirsky, King ve Diener, 2005; Ünüvar ve diğer., 2015). Samimi, güvenli ve destekleyici ortamlar bireyde mutluluk ve özgüveni artırırken, psikolojik sorunlara eğilimi de azalta-bilmektedir (Ünüvar ve diğer.2015, s. 2).

Mutluluğun yapısını tanımlamada kültürel farklılıklar bulunabilmektedir. Batılı ülkelerde olumlu hislerin en yüksek seviyeye çıarılması, olumsuz duyguların ise en düşük seviyeye indirilmesi bir yaşam amacı olarak görülmektedir. İyi oluş terimi, insanlığın oluşundan beri sorgulanan bir kavramdır. Bireylere, toplumlara, zamana ve kültürlere göre çoğunlukla farklı tanımlamaları olmuştur. Genelde yaşamdan elde edilen tatmin iyi olmanın besleyicisi olarak görülmüştür (Sarıcaoğlu, 2011, s. 1). Manevi doyumda birçok farklı etmenler etkili olabilmektedir. Bunlar maddi kaynaklı olabileceği gibi manevi kaynaklı olabilmektedir. Günümüzde insanlara "sizleri neler mutlu eder?” diye sorulduğunda "arzuladıklarımızı alabilmektir" cevab1 verilebilmektedir. Her istediğimizi satın almayı ve yapmayı sağlayabilecek tüketim, günümüzde insanların önemli bir mutluluk kaynağı olabilmektedir (Şentürk, 2008, s. 231). Fakat bu mutluluk bireyde devamlı bir mutluluğun sağlanmasında yeterli olmayabilmektedir. Mutluluğun devamlığında manevi duygular ön plana çıkabilmektedir. Bu noktada kişilerin sosyal yaşam alanları büyük önem taşımaktadır.

Bireylerin mutluluğu sağladığı en önemli sosyal yaşam alanlarının başında aile ortamı gelmektedir. Özellikle ergenlerde aile içi iletişim düzeyi önemlidir (Aypay ve Eryllmaz, 2011, s. 193). Ergenlik, çocukluk ile yetişkinlik arasında bir geçiş dönemi olarak kabul edilmektedir. Bu dönemde yalnız biyolojik değişiklikler değil, aynı zamanda toplumsal ve psikolojik değişiklikler de ortaya çıkar. Ergenler bu dönemde fiziksel, duygusal zihinsel ve toplumsal bir yetişkin olma yolunda hızlı ve önemli adımlarla gelişirler. Ayrıca bu dönemin başarılı bir şekilde kazanılması ve yaşanması için bazı önemli gelişim görevlerinin yerine getirilmesi gerekir. Bunlar; ebeveynlerden ve diğer yetişkinlerden duygusal yönden bağımsızlaşma, toplumsal sorumluluklar da yer almayı isteme ve bu sorumlulukları kazanma, davranışlarını yön verecek gelişmiş bir değerler grubuna ve ahlak sistemine sahip olmaktır (Sar1 ve diğerleri, 2007, s. 298). Sonuç olarak aile; oluşturan fertlerinin fiziksel ve psikolojik sağlığı için gerekli saygı, sevgi, yakın ilgi ve şefkati bulabilecekleri en rahatlatıcı ve doğal ortamdır (Aral ve Sağlam, 2012, s. 72). Bu nedenle, bireyin mutluluğunda ailenin çok önemli bir etkisi ve yeri vardır. Sağlıklı toplumun oluşturulmasında mutlu 
fertlerden oluşan aileler ile sağlanabilir. Aile, birey ve toplum arasındaki dengeyi oluşturabilmektedir (Arıkan 1996, s. 152). Aile içerisinde birey için en önemli yapı anne ve babanın çocuğa ve kardeşlerine göstermiş olduğu tavırdır (Karaaslan, 2010, s. 13). Anne babanın çocuklara göstermiş olduğu sevgi ve yüklemiş olduğu sorumluluğun dengeli veya dengesiz dağılımı çocuklarda farklı algılara yol açabilmektedir. Bunun akademik başarı veya suça olan etkisine yönelik birçok araştırma bulunmaktadır (Boydak ve Yüksel, 2003; Erdoğdu, 2007; Hacıfazlıoğlu ve diğer., 2015; Keskin ve Sezgin, 2009; Saral, 1993; Topses, 2013; Yılmaz ve diğer., 2012). Fakat kardeş sayısının sadece mutluluğa etkisine yönelik çalışmaların oldukça sınırlı düzeyde olduğu görülmüştür. Literatürde, ergenlerin mutlulukla aynı anlamda kullanılabilen kissisel iyi oluşları üzerinde aile ve kardeş özelliklerinin önemli etkileri olduğuna ilişkin çalışmalar bulunmaktadır.

Oskay (1986:222), 500 lise öğrencisinin katılımı ile ergen anne-baba çatışma durumunu incelemiştir. $\mathrm{Bu}$ araştırmada, bulundukları aile içindeki çocuk sayısına göre öğrencilerin ebeveynleri ile çatışma düzeylerinin incelendiğinde ilk sırayı, en yüksek çatışma indeks ortalamasına beş ve daha fazla çocuğu bulunan aile grubunun sahip olduğu bulunmuştur. Bu aile grubunu tek çocuklu aileler izlemiştir. Ebeveynleri ile çatışma düzeyi en düşük çatışma indeks ortalaması ile iki çocuklu ailelerde görülmüştür. Çocuk sayısı yükseldikçe çatışma indeks ortalaması da artış göstermiştir. Bu bulgulara göre ebeveynleri ile en çok çatışmakta olanlar, kardeşi bulunmayan tek çocuklar ile beş ve daha fazla çocuğu bulunan kalabalık ailelerde kardeş sayısı fazla olan çocuklardır. Araştırmacı bunu tek çocukların aşırı ilgi ile şımartılmasına, beş çocuklu ailelerde ise ailenin yeterince çocuklara özel bir zaman ayıramamasına bağlamaktadır. Ask, Kurki ve Paavlianien'in (2003) gerçekleştirdikleri araştırmaya göre; ergenin kendisini aileden dışlanmış algılamaması, iletişimde güvenin sağlanması, aile içerisinde iletişim kanallarının açık olması, karşılıklı duygusal yakınlı̆ı̆n olması durumunda ergenlerin öznel iyi oluş halleri de olumlu etkilenmektedir (Akt: Eryilmaz, 2009, s. 977).

Joronen ve Kurki'ye (2005) göre, ergenin iyi oluşunu etkileyen etmenler; sevgi ve sayg1 içeren güvenli ev ortamı, aile üyesinin aileye katılımı, açık ileţşim, aile içinde bireysel önemsenme duygusunun hissedilmesi ve dışsal ilişkilerdir. Benzer şekilde Park'n (2004) gerçekleştirmiş olduğu araştırmaya göre ergen öznel iyi oluşunu etkileyen etmenler; olumlu yaşam olaylarını deneyimlemek, destekleyici ebeveyne sahip olmak, zor işlerin üstesinden gelmek ve önemli kişilerle gerçekleştirilen ilişkiden yüksek seviyede haz almaktır (Akt: Eryllmaz, 2010, s. 977-978). Tatlıoğlu (2012, s. 2857), 225 üniversite öğrencisi ile gerçekleştirmiş olduğu çalışmaya göre göre; farklı kardeş sayılarına sahip olan üniversite öğrencilerinin özerklik, çevresel hâkimiyet, bireysel gelişim puan ortalamaları arasında anlamlı bir farklılık olmadığını bulmuştur. Ayrıca farklı kardeş sayılarına sahip olan üniversite öğrencilerinin yaşam amaçları, diğer arkadaşları ile olumlu ilişkiler, öz-kabul puan ortalamaları arasında istatistiksel olarak anlamlı bir farklılık olmadığ sonucuna ulaşmıştır.

Yukarıda açılanan araştırma sonuçlarına göre, gençlerin mutluluğunda aile içi ilişkilerin etkisi olmaktadır. Çok çocuklu ailelerde çocuklarına yeterince ilgi göstermeme durumu yaşayabilirken, tek çocuklu aileler çocuklarını şımartma ve kuralsız bir yaşam ortamı sağlayabilmektedir. Kardeş sayısı ile mutluluk arasında tam bir ilişki saptanamamışır. Bu durum da çocuklar için mutluluk sağlayabilmektedir.

Fakat toplumumuzda bu konu ile ilgili genel yargilar bulunmaktadır. Toplu-muzda genel yarg1 olarak tek çocuğun mutsuz olduğuna ve mutlaka en az bir kardeşinin olmasının gerektiğine dair genel bir inanış bulunmaktadır. Bu çalışmada, kardeş durumuna göre, mutluluk düzeyleri arasındaki ilişki araştırılarak bu genel toplumsal yargının doğruluğu araştırılmaktadır.

\section{Araştırma Problemleri ve Alt Problemler}

Bu araştırmada, "kardeş özelliklerine göre lise öğrencilerinin mutluluk düzeyleri farklilık göstermekte midir?” sorusuna cevap aranmıştır. Bu problemin çözümünde aşağıdaki alt problemlere yanıt aranmışır, s.

1. Kardeş durumuna göre lise öğrencilerinin mutluluk puanları istatistiksel olarak anlamlı bir farkllık göstermekte midir?

2. Ögrencilerin cinsiyetlerine göre mutluluk puanları istatistiksel olarak anlamlı bir farklılık göstermekte midir?

3. Kardeş cinsiyetine göre lise öğrencilerinin mutluluk puanları istatistiksel olarak anlamlı bir farklilık göstermekte midir?

4. Kardeş yaş düzeyine göre lise öğrencilerinin mutluluk puanları istatistiksel olarak anlamlı bir farklillk göstermekte midir? 


\section{Yöntem}

$\mathrm{Bu}$ araştırmada öğrencilerin kardeş özelliklerine göre mutluluk düzeylerinin farklılık gösterip göstermediğini belirlemek amacıyla betimsel tarama yöntemi kullanılmıştır. Tarama yöntemi, geçmişte olan ya da halen var olan bir durumu olduğu biçimiyle tanımlamayı amaçlayan araştırma yöntemidir. Araştırmaya konu olan durum, nesne ya da birey, kendi mevcut durumları içinde ve olduğu gibi tanımlamaya çalışır (Karasar, 2007, s. 77). Bu kapsamda araştırmada, mevcut durumu açıklamak amacıyla ilişkisel tarama modeli kullanılmıştır. Araştırmanın bağımsız değişkeni öğrencilerin cinsiyet, kardeş sayısı, kardeşlerin yaşıdır. Araştırmanın bağımlı değişkeni ise öğrencilerin mutluluk düzeyi puanlarıdır. Öğrencilerin mutluluk düzeylerinin farklı bağım-sız değişkenlerle karşılaştırmasında bağımsız t testi, Tek Yönlü ANOVA testi ve farkların analizinde Scheffe testinden yararlanılmıştır. SPSS 16.0 programına girilen veriler çözümlemelerle analizleri gerçekleştirilmiştir.

\section{Evren- Örneklem}

Araştırma kapsamında ölçek uygulaması Çanakkale Merkez İlçesinde eğitimlerini sürdürmekte olan 489 ortaöğretim öğrencisinin katılımı ile gerçekleştirilmiştir. Katılımcıların cinsiyete göre dağılımları (Tablo 1) incelendiğinde erkek ve kız öğrenci sayılarının birbirlerine yakın olmakla beraber erkek öğrenci sayısının kız öğrencilere göre sayılarının biraz daha fazla olduğu görülmektedir.

Tablo 1. Katullmmclarm Cinsiyetlerine Göre Dă̆gllmı

\begin{tabular}{ccc}
\hline Cinsiyet & $\boldsymbol{f}$ & $\boldsymbol{\%}$ \\
\hline Erkek & 251 & 51,3 \\
$\mathrm{~K} z \mathrm{z}$ & 238 & 48,7 \\
\hline Toplam & 489 & 100,0 \\
\hline
\end{tabular}

Tablo 2'de katılımcıların kardeş sayısına göre dağılımları görülmektedir. Öğrencilerin büyük çoğunluğu tek kardeşli $(\% 42,5)$ olduğu görülmektedir. Bunu iki kardeşli $(\% 22,9)$ ve kardeşi olmayanlar $(\% 19,2)$ takip etmektedir. Aileler çoğunlukla küçük ailelerden oluşmaktadır. 4 ve üzeri çocuklu olan ailelerin oranı yaklaşık \%15'tir.

Tablo 2. Katılımolarn Kardeş Sayısına Göre Dă̆ılımı

\begin{tabular}{ccc}
\hline Kardes Sayisi & $\boldsymbol{f}$ & $\boldsymbol{\%}$ \\
\hline Yok & 94 & 19,2 \\
1 & 208 & 42,5 \\
2 & 112 & 22,9 \\
3 & 37 & 7,6 \\
4 ve üzeri & 38 & 7,8 \\
\hline Toplam & 489 & 100 \\
\hline
\end{tabular}

Tablo 3' de katılımcıların yaşlarına göre dağılımları görülmektedir. Öğrencilerin büyük çoğunluğu 16 $(\% 29,9), 15(\% 27,2)$ ve $17(\% 21,7)$ yaşlarında oldukları görülmektedir.

Tablo 3. Katılımcılarn Yaşlarna Göre Dăğlımı

\begin{tabular}{ccc}
\hline Katulimc1 Yaş1 & $\boldsymbol{f}$ & $\boldsymbol{\%}$ \\
\hline 14 & 50 & 10,2 \\
15 & 133 & 27,2 \\
16 & 146 & 29,9 \\
17 & 106 & 21,7 \\
18 & 54 & 11,0 \\
\hline Toplam & 489 & 100,0 \\
\hline
\end{tabular}

\section{Veri Toplama Araçları}

Oxford Mutluluk Ölçeğg. Bu araştırmanın verileri, Hills ve Argyle tarafından geliştirilmiş ve Doğan ve Sapmaz (2012) tarafindan Türkçeye uyarlaması gerçekleştirilen “Oxford Mutluluk Ölçeği” ile toplanmıştır. Doğan ve Sapmaz (2012) güvenilirliği; iç tutarllık, bileşik güvenilirlik ve test yarılama yöntemlerini 
kullanarak incelemişlerdir. Yapmış oldukları testlerin sonucunda; test yarılama yöntemiyle güvenilirlik katsayıs 1 0,6; ölçeğin iç tutarlılık katsayısı 0,91 olarak hesaplanmıştır. Araştırma kapsamında gerçekleştirilen uygulamada Croanbach $\alpha$ güvenirlik katsayısı 0,76 olarak bulunmuştur.

\section{Verilerin Analizi}

Araştırmada, mevcut durumu açıklamaya yönelik olarak iliş̧kisel tarama yöntemi kullanılmıştır. Araşıırmanın bağımsız değişkenleri katılımcıların kardeş özellikleri (sayısı, cinsiyeti, geçirilen süre) ve bağımlı değişkeni katılımcıların mutluluk düzeyleridir. Araştırmada katılımcıların kardeş durumları belirlenerek, bu özelliklerin katılımcıların mutluluk düzeylerine göre farklılaşma durumu istatistik analiz programı olan SPSS 16.0 kullanılarak çözümlenmiştir. Verilerin çözümlenmesinde Aritmetik Ortalama, Standart Sapma, t- testi, Tek Yönlü ANOVA, Scheffe testleri kullanılmıştır.

\section{Bulgular}

Araştırmanın temel problemi, kardeş özelliklerine göre öğrencilerin mutluluk düzeylerinin farklllaşma durumunu belirlemektedir. Bu problemin çözümü için katılımcıların kardeş özellikleri farklı alt problemler olarak belirlenmiştir. Alt bulgu bölümlerinde belirlenen alt problemlere ilişkin elde edilen verilere yer verilmiştir.

\section{Birinci Alt Probleme Ait Bulgular}

Araştırmanın birinci alt problemi "Kardeş sayllarına göre lise öğrencilerinin mutluluk puanları istatistiksel olarak anlamlı bir farklılık göstermekte midir?” şeklinde belirlenmiştir. Kardeş sayısına göre anlamlı bir farkın olup olmadığını ortaya koymak için Tek Yönlü (One-Way) Anova testi analiz yöntemi kullanılmış ve elde edilen bulgular Tablo 4'te verilmiştir. Buna göre farklı kardeş sayısına göre mutluluk düzeyle-rinde anlamlı bir farklılık olmadığ $\left[\mathrm{F}_{(3-485)}=0,391, \mathrm{p}>0,05\right]$ bulunmuştur

Tablo 4. Kardes Sayısına Göre Mutluluk Puanlarmın Tek Yönlü ANOV A Sonuçları

\begin{tabular}{cccccc}
\hline Varyansin Kaynağı & $\begin{array}{c}\text { Kareler } \\
\text { Toplami }\end{array}$ & $\boldsymbol{s d}$ & KO & $\boldsymbol{F}$ & $\boldsymbol{P}$ \\
\hline Gruplararası & 249,365 & 3 & 83,12 & 0,39 & 0,76 \\
Gruplariçi & 103044,7 & 485 & 212,46 & & \\
\hline Toplam & 25 & & & & \\
\hline
\end{tabular}

$\left({ }^{*} \mathrm{p}<0,05,{ }^{* *} \mathrm{p}<0,01,{ }^{* * *} \mathrm{p}<0,001\right)$

Kardeş sayısına göre mutluluk ölçeği toplam puanlarının değiş̧imi Tablo 5'te incelendiği zaman en mutlu olanların tek kardeşi olanlar olduğu (94,91), onları iki kardeşi olanlar ve kardeşi olmayanlar izlemektedir. En düşük mutluluk puanını 3 ve üzeri kardeş sayısına $(93,23)$ sahip olanlara aittir. Puanlar birbirlerine yakın olduğu için anlamlı bir fark ortaya çıkarmamıştır.

Tablo 5. KardeşS Sayısına Göre Mutluluk Ölçeği Puanlarmm Dağzllmı

\begin{tabular}{cccc}
\hline Kardeş Sayıs $\mathbf{1}$ & $\boldsymbol{N}$ & $\overline{\boldsymbol{X}}$ & $\boldsymbol{S d}$ \\
\hline Yok & 94 & 93,48 & 15,10 \\
1 & 208 & 94,91 & 15,53 \\
2 & 112 & 93,69 & 12,11 \\
3 ve üzeri & 75 & 93,23 & 14,53 \\
\hline Toplam & 489 & 94,10 & 14,55 \\
\hline
\end{tabular}

\section{İkinci Alt Probleme Ait Bulgular}

Araştırmanın ikinci alt problemi "Kız ve erkek öğrencilerin "Öğrencilerin cinsiyetlerine göre mutluluk puanları istatistiksel olarak anlamlı bir farklılık göstermekte midir?” şeklinde belirlenmiştir. Katılımcıların cinsiyetlerine göre mutluluk puanları arasında anlamlı bir farkın olup olmadığını ortaya koymak için $t$ testi (bağımsız gruplar için) analiz yöntemi ile değerlendirilmiş ve elde edilen bulgular Tablo 6' da verilmiştir. 
Tablo 6. Cinsiyet Durumuna Göre Öğrencilerin Mutluluk Puanlarna İlişkin Bağımsız. t-Testi Sonuçlar

\begin{tabular}{cccccc}
\hline Varyansin Kaynă̆ 1 & $\boldsymbol{N}$ & $\overline{\boldsymbol{X}}$ & $\boldsymbol{d f}$ & $\boldsymbol{t}$ & $\boldsymbol{p}$ \\
\hline Erkek & 251 & 92,32 & 15,39 & 487 & $-2,80$ \\
$\mathrm{~K} 1 \mathrm{z}$ & 238 & 95,98 & 13,37 & & \\
\hline
\end{tabular}

$\left({ }^{*} \mathrm{p}<0,05,{ }^{* *} \mathrm{p}<0,01,{ }^{* * *} \mathrm{p}<0,001\right)$

Cinsiyete göre mutluluk puanları arasında anlamlı bir farklılık olduğu $\left[\mathrm{t}_{(487)}=-2,80, \mathrm{p}<0,001\right]$ Tablo 6 'da görülmektedir. Tabloda erkek öğrencilerin toplam mutluluk puanlarının ortalaması, kızların mutluluk puan ortalamasından yaklaşık 4 puan daha azdır. Kız öğrenciler erkek öğrencilere göre daha mutlu olduklarını belirtmişlerdir.

\section{Üçüncü Alt Probleme Ait Bulgular}

Araştırmanın üçüncü alt problemi “Kardeş cinsiyetine göre lise öğrencilerinin mutluluk puanları istatistiksel olarak anlamlı bir farklılık göstermekte midir?” şeklinde belirlenmiştir. Kardeş cinsiyetinin kendi cinsiyeti ile benzer ya da farklı olma durumuna göre mutluluk düzeylerinin anlamlı bir farkın olup olmadığını ortaya koymak için Tek Yönlü (One-Way) ANOVA testi kullanılarak değerlendirilmiş ve bulgular Tablo 7'de gösterilmiştir. Buna göre öğrencilerin kardeş cinsiyetlerinin aynı veya farklı olmasına göre toplam mutluluk puanlarında bir farklılık olmadığ1 $\left[\mathrm{F}_{(2-392)}=1,06, \mathrm{p}>0,05\right]$ bulunmuştur.

Tablo 7. Kardeș Cinsiyet Benzẹlik/Farklhlı Durumuna Göre Mutluluk Puanlarmın Tek Yönlü ANOVA Sonuclar

\begin{tabular}{cccccc}
\hline Varyansın Kaynă̆ı & $\begin{array}{c}\text { Kareler } \\
\text { Toplami }\end{array}$ & $\boldsymbol{s d}$ & KO & $\boldsymbol{F}$ & $\boldsymbol{P}$ \\
\hline Gruplararası & 439.20 & 2 & 219,60 & 1,06 & 0,35 \\
Gruplariçi & 81594,48 & 392 & 208,15 & & \\
\hline Toplam & 82033,69 & 394 & & & \\
\hline
\end{tabular}

$\left({ }^{*} \mathrm{p}<0,05,{ }^{* *} \mathrm{p}<0,01,{ }^{* * *} \mathrm{p}<0,001\right)$

Öğrencilerin kardeş cinsiyetinin benzer ya da farklı olma durumuna göre mutluluk ölçeği toplam puanlarının değişimi incelendiği zaman (Tablo 8) en mutlu olanların farklı cinsiyette $(95,39)$ kardeşi olanların olduğu görülmektedir. Aynı cinsiyette kardeşi olanlar diğerlerine göre mutluluk puanları $(92,88)$ en düşük olmasına rağmen diğer gruplarla fark yaratacak düzeyde değildir.

Tablo 8. Kardeș Cinsiyetinin Benz̨erlik/Farklulık Durumuna Göre Mutluluk Puanlarmın Dă̆llım

\begin{tabular}{cccc}
\hline Kardes Cinsiyet Durumu & $\boldsymbol{N}$ & $\overline{\boldsymbol{X}}$ & $\boldsymbol{S d}$ \\
\hline Aynı Cinsiyet & 132 & 92,88 & 14,02 \\
Her İki Cinsiyet & 119 & 94,38 & 14,55 \\
Farkl Cinsiyet & 144 & 95,39 & 14,69 \\
\hline Toplam & 395 & 94,25 & 14,43 \\
\hline
\end{tabular}

Öğrencilerin kardeşlerinin cinsiyetlerine göre anlamlı bir farkın olup olmadı̆̆ını belirlemek amacıyla Tek Yönlü (One-Way) Anova testi analiz yöntemi ile değerlendirilmiş ve elde edilen bulgular Tablo 9'da gösterilmiştir. Buna göre kızların farklı cinsiyette kardeşlerine göre toplam mutluluk puanlarında bir farklılık olmadığ1 $\left[\mathrm{F}_{(2-392)}=4,12, \mathrm{p}>0,05\right]$ bulunmuştur.

Tablo 9. Kardeş Cinsiyetine Göre Mutluluk Puanlarmın Tek Yönlü ANOV A Sonucları

\begin{tabular}{cccccc}
\hline Varyansin Kaynă̆1 & $\begin{array}{c}\text { Kareler } \\
\text { Toplami }\end{array}$ & $\boldsymbol{s d}$ & KO & F & P \\
\hline Gruplararası & 1687,54 & 2 & 843,77 & 4,12 & $0,017^{*}$ \\
Gruplariçi & 80346,15 & 392 & 204,97 & \\
\hline Toplam & 82033,68 & 394 & & & \\
\hline
\end{tabular}

$(* \mathrm{p}<0,05, * * \mathrm{p}<0,01, * * * \mathrm{p}<0,001)$ 
Kardeş cinsiyetine göre mutluluk ölçeği toplam puanlarının değişimi incelendiği zaman (Tablo 10) en mutlu olanların sadece kız kardeşi olanların $(97,16)$ olduğu görülmektedir. Sadece erkek kardeşi olanların ise diğer öğrencilere göre mutluluk puanlarının daha düşük olduğu görülmektedir.

Tablo 10. Kardeş Cinsiyetinin Benžerlike/Farklllk Durumuna Göre Mutluluk Puanlarmin Dă̆llamı

\begin{tabular}{cccc}
\hline Kardes Cinsiyet Durumu & $\boldsymbol{N}$ & $\overline{\boldsymbol{X}}$ & $\boldsymbol{S d}$ \\
\hline Sadece Erkek & 163 & 92,13 & 14,14 \\
Her İki Cinsiyet & 119 & 94,38 & 14,55 \\
Sadece Kiz & 113 & 97,16 & 14,33 \\
\hline Toplam & 395 & 94,25 & 14,43 \\
\hline
\end{tabular}

Anlamlı farkın kaynağını belirlemek amacıyla kullanılan Scheffe Testi sonu-cunda (Tablo 11) sadece erkek kardeşi olan öğrenciler ile sadece kız kardeşi olduğunu belirtenler arasında anlamlı bir farkın $(\mathrm{p}<0,05)$ olduğu görülmüştür.

Tablo 11. Kardeş Cinsiyetine Göre Ögrencilerin Mutluluk Puan Ortalamalarn Arasindaki Farklihğgn Anlamhliğna İliskin Scheffe Testi Sonuclarn

\begin{tabular}{|c|c|c|c|c|c|c|}
\hline \multirow{2}{*}{ Gruplar } & \multirow{2}{*}{ Gruplar } & \multirow{2}{*}{$\begin{array}{l}\text { Ortalamalarin } \\
\text { Farkı }\end{array}$} & \multirow{2}{*}{$\begin{array}{l}\text { Standart } \\
\text { Hata }\end{array}$} & \multirow{2}{*}{$p$} & \multicolumn{2}{|c|}{ \%95 Güven Aralı̆̆1 } \\
\hline & & & & & Alt Sinir & Üst Sinit \\
\hline \multirow[t]{2}{*}{ Sadece Erkek } & Hem Erkek Hem Kız & $-2,24$ & 1,73 & 0,43 & $-6,48$ & 1,99 \\
\hline & Sadece Kız & $-5,02 *$ & 1,75 & $0,02^{*}$ & $-9,33$ & $-0,72$ \\
\hline \multirow{2}{*}{$\begin{array}{l}\text { Hem Erkek Hem } \\
\text { Kız }\end{array}$} & Sadece Erkek & 2,24 & 1,73 & 0,43 & $-1,99$ & 6,48 \\
\hline & Sadece K1z & $-2,78$ & 1,88 & 0,34 & $-7,40$ & 1,84 \\
\hline \multirow[t]{2}{*}{ Sadece Kiz } & Sadece Erkek & 5,02 & 1,75 & $0,02^{*}$ & 0,72 & 9,33 \\
\hline & Hem Erkek Hem Kız & 2,78 & 1,88 & 0,34 & $-1,84$ & 7,40 \\
\hline
\end{tabular}

$\left({ }^{*} \mathrm{p}<0,05,{ }^{* *} \mathrm{p}<0,01,{ }^{* * *} \mathrm{p}<0,001\right)$

\section{Dördüncü Alt Probleme Ait Bulgular}

Araştırmanın dördüncü alt problemi "Kardeş yaş düzeyine göre lise öğrencilerinin mutluluk puanları istatistiksel olarak anlamlı bir farklılık göstermekte midir?” şeklinde belirlenmiştir. Yaş düzeyine (kardeşlerinden büyük, küçük, orta yaş grubunda) göre mutluluk puanlarının anlamlı bir farkın bulunma durumunu belirlemek için Tek Yönlü (One-Way) Anova testi kullanılmış ve bulgular Tablo 12'de gösterilmiştir. Buna göre farklı yaş kategorisinde olan öğrencilerin toplam mutluluk puanlarında bir farklılık olduğu $\left[\mathrm{F}_{(2-392)}=3.46, \mathrm{p}<.05\right]$ bulunmuştur.

Tablo 12. Yass Düzeylerine Göre Mutluluk Puanlarmın Tek Yönlü ANOV A Sonucları

\begin{tabular}{cccccc}
\hline Varyansin Kaynă̆ı & $\begin{array}{c}\text { Kareler } \\
\text { Toplami }\end{array}$ & $\boldsymbol{s d}$ & $\boldsymbol{K O}$ & $\boldsymbol{F}$ & $\boldsymbol{P}$ \\
\hline Gruplararası & 1422,58 & 2 & 711,29 & 3,46 & $0,032^{*}$ \\
Gruplariçi & 80611,11 & 392 & 205,64 & & \\
\hline Toplam & 82033,686 & 82033,686 & 394 & & \\
\hline
\end{tabular}

$\left({ }^{*} \mathrm{p}<0,05,{ }^{* *} \mathrm{p}<0,01,{ }^{* * *} \mathrm{p}<0,001\right)$

Yaş düzeyine göre mutluluk ölçeği toplam puanlarının değişimi incelendiği zaman (Tablo 13) en mutlu olanların küçük $(95,64)$ ve büyük kardeşlerin $(94,57)$ olduğu görülmektedir. Ortanca kardeşlerin mutluluk puanlarının diğer gruplara göre daha düşük $(90,66)$ olduğu görülmektedir.

Tablo 13. Yaş Düreylerine Göre Mutluluk Puanlarmmn Dağglımı

\begin{tabular}{cccc}
\hline Yas Düzeyi & $\boldsymbol{N}$ & $\overline{\boldsymbol{X}}$ & $\boldsymbol{S d}$ \\
\hline Küçük Kardeş & 111 & 94,57 & 13,70 \\
Ortanca & 90 & 90,86 & 12,92 \\
Büyük Kardeş & 194 & 95,64 & 15,29 \\
\hline Toplam & 395 & 94,25 & 14,43 \\
\hline
\end{tabular}


Anlamlı farkın kaynağını belirlemek amacıyla kullanılan Scheffe Testi sonucunda (Tablo 14) sadece erkek kardeşi olan ögrenciler ile sadece kız kardeşi olduğunu belirtenler arasında anlamlı bir farkın $(\mathrm{p}<0,05)$ olduğu görülmüştür.

Tablo 14. Yass Düzeylerine Göre Öğrencilerin Mutluluk Puan Ortalamalar Arasındaki Farkhliğnn Anlamlliğgna Ilisskin Scheffe Testi Sonuçlar

\begin{tabular}{|c|c|c|c|c|c|c|}
\hline \multirow{2}{*}{ Gruplar } & \multirow{2}{*}{ Gruplar } & \multirow[t]{2}{*}{ Ortalamaların Fark1 } & \multirow[t]{2}{*}{ Standart Hata } & \multirow[t]{2}{*}{$p$} & \multicolumn{2}{|c|}{ \%95 Güven Aralü̆1 } \\
\hline & & & & & Alt Sinir & Üst Sinit \\
\hline \multirow[t]{2}{*}{ Büyük } & Ortanca & 3,71 & 2,03 & 0,19 & $-1,29$ & 8,71 \\
\hline & Küçük & $-1,07$ & 1,71 & 0,82 & $-5,27$ & 3,12 \\
\hline \multirow[t]{2}{*}{ Ortanca } & Büyük & $-3,71$ & 2,03 & 0,19 & $-8,71$ & 1,29 \\
\hline & Küçük & $-4,78$ & 1,83 & $0,03 *$ & $-9,28$ & $-0,29$ \\
\hline \multirow[t]{2}{*}{ Küçük } & Büyük & 1,07 & 1,71 & 0,82 & $-3,12$ & 5,27 \\
\hline & Ortanca & $4,78^{*}$ & 1,83 & $0,03 *$ & 0,29 & 9,28 \\
\hline
\end{tabular}

$$
\left({ }^{*} \mathrm{p}<0,05,{ }^{* *} \mathrm{p}<0,01, * * * \mathrm{p}<0,001\right)
$$

Bu bölümde, kardeş sayısının mutluluğa etkisini belirlemeye yönelik belirlenen alt problemlere ilişkin bulgulara yer verilmiştir. Elde edilen bulgular ışığında kardeş sayısına göre mutluluk puanlarının anlamlı bir farkll1ık göstermediği bulunmuştur. Tek kardeşi olanların en mutlu öğrenci grubu olduğu bulunmuştur. Onları iki kardeşi olanlar ve kardeşi olmayanlar izlemektedir. Cinsiyet durumuna göre kızların erkeklere göre daha mutlu oldukları görülmüştür. Kardeş cinsiyetinin aynı veya farklı olmasına göre mutluluk puanlarının anlamlı bir farklılık göstermediği görülmüştür. Kardeş cinsiyetinin kız veya erkek olmasına göre mutluluk puanlarının anlamlı bir farklılık gösterdiği bulunmuştur. Buna göre sadece kız kardeşi olanlar, sadece erkek ve hem erkek hem de kız kardeşi olanlara göre daha mutlu oldukları bulunmuştur. Öğrencilerin kardeşlerine kıyasla yaş durumuna göre mutluluk düzeylerinin anlamlı bir farkllık gösterdiği bulgusuna ulaşılmıştır. Büyük ve küçük kardeşler ortanca kardeşlere göre daha mutlu olduklarını belirtmişlerdir.

\section{Tartışma, Sonuç ve Öneriler}

Araştırmada elde edilen bulgulara dayalı aşağıda belirtilen sonuçlara ulaşılmıştır.

Kardeş sayısına göre mutluluk puanlarının anlamlı bir farklılık göstermediği bulunmuştur. Bu sonuç; gençlerin iyi hal durumları ile kardeş sayısı arasında bir iliş̧ki bulunmadığını belirten Çivitçi (2009), Tatlıoğlu (2012) ve Tuncer vd. (2014) elde ettiği sonuçlar ile örtüşmektedir.

Katılımcılardan tek kardeşi olanların en mutlu öğrenci grubu olduğu bulun-muştur. Onları iki kardeşi olanlar ve kardeşi olamayanlar izlemektedir. Kardeş sayısı 3 ve üzeri olanların mutluluk puanlarında kademeli bir azalma görülmüştür. Bu durumun ortaya çıkmasında ailelerin genel gelir düzeyinin düşük olmasından dolayı çok çocuklu ailelerde çocukların maddi ihtiyaçlarının karşılanmasında sıkıntılar neden olabilir. Tek çocuklarda maddi olanaklar yeterli düzeyde sağlanabilse bile kardeşiyle yaşayabileceği sosyal paylaşım olanaklarının olmaması, yalnızlığa ve daha az mutlu olmasına yol açabilir. Çok çocuklu ailelerde çocukların akademik başarılarının daha düşük olduğu ve suça daha meyilli olduklarına dair araştırmalara yer verilmişti. Oskay (1986, s. 228) çok çocuklu ailedeki çocukların aileleri ile tartışmaya daha meyilli olduklarını onları tek çocuklu ailelerde bulunan çocuklar takip ettiğini belirtmiştir. Topses (2013, s. 701) çok çocuklu ailelerdeki (özellikle beş ve üzeri) bireylerin olumsuz davranışlara daha meyilli olduklarını belirlemiştir. Hacıfazlıoğlu vd. (2015, s. 91) iki çocuklu ailelerdeki lise öğrencilerin akademik başarılarının ve özgüvenlerinin daha yüksek olduğu belirtmiştir. Çok kardeşi (üç ve daha fazla) olan katilımcıların mutluluk durumu bizim gerçekleştirdiğimiz araştırmada da düşük çıkmıştır. Elde edilen verilere ve yer verilen akademik çalısmaya göre üç ve üzeri kardeş sayısı mutluluğu arttırmamakta, aile içi tartısmalara ve akademik başarıda düşüşe yol açabilmektedir.

Cinsiyet durumuna göre kıların erkeklere göre daha mutlu oldukları görülmüştür. TÜIK 2014 verilerine, Boyd (2014), Çivitci (2009) ile Çopur vd. (2015) araştırma sonuçlarına göre de kadınlar erkeklerden daha mutlu durumdadırlar. Bu sonuç Akın ve Şentürk (2012) cinsiyet ve mutluluk ile ilişkili elde ettiği bulgu ile örtüşmemektedir. Kız öğrencilerin erkek öğrencilere göre daha mutlu olmalarında hayata bakış açılarının daha olumlu olması etkili olmuş olabilir. 
Kardeşin cinsiyetinin kendisi ile aynı veya farklı olması durumuna göre mutluluk puanlarının anlamlı bir farklıllk göstermediği görülmüştür. Kardeş cinsiyetinin kız veya erkek olmasına göre mutluluk puanlarında anlamlı bir farklılık bulunmuştur. Kız kardeşi olanlar, her iki cinsiyette de kardeşi olanlara ve sadece erkek kardeşi olanlara kıyasla daha mutlu oldukları belirlenmiştir.

Öğrencilerin kardeşlerine kıyasla yaş durumuna (büyük, ortanca, küçük) göre mutluluk düzeylerinin anlamlı bir farkllı1k gösterdiği sonucuna ulaşılmıştır. Kardeşlerinden küçük ve büyük olanlar ortanca olanlara göre daha mutlu dolduklarını belirtmişlerdir. Samurçay (1982, s. 9) en küçüklerin, kendilerini küçük, zayıf hissetmekten çok mutlu olduklarını, bu durumdan dolayı kendilerini ailede ayrıcalıklı saydıklarını belirtmektedir.

Elde edilen veriler ışığında ailenin çocuklarına verdiği değer ve ayırdıkları zaman çok önem teşkil etmektedir. Bu nedenle ailelerin maddi ve manevi ihtiyaçlarını karşılayabilecekleri ve ilgi gösterebilecekleri sayıda çocuğa sahip olmalarının daha önemli olduğu anlaşılmaktadır. İlgi gösterilmeyen ve önemsenmeyen her birey ileride daha farklı şekilde toplum önüne çıkmaktadır. Önemsenen ve değer gösterilen mutlu çocukların ileride özgüveni artmış, sorumluluk sahibi bireyler olarak topluma katk1 getirecekleri düşünülmektedir. Araştırmada elde edilen bulgular ve sonuçlar doğrultusunda aşağılda belirtilen öneriler getirilmiştir:

a) Anne ve babanın çocuklara yönelik tutum ve davranıslara yer verilerek çalısma farklı bir boyuttan incelenebilir.

b) Aile ve kardeşlerle geçirilen zaman boyutlarına yer verilerek aile ve kardeşlerle geçirilen kaliteli zamanın mutluluğa etkisi incelenebilir.

\section{Etik Beyan}

"Kardeş Durumu ve Mutluluk: Çanakkale'de Lise Öğrencileri Üzerine Bir Araştırma” başlıklı çalışmanın yazım sürecinde bilimsel, etik ve alıntı kurallarına uyulmuş; toplanan veriler üzerinde herhangi bir tahrifat yapılmamıs ve bu çalışma herhangi başka bir akademik yayın ortamına değerlendirme için gönderilmemiştir.

\section{Kaynakça}

Akın, A. (2008). Psikolojik iyi olma ölçekleri: Geçerlik ve güvenirlik çalşması. Kuram ve Uygulamada Eğitim Bilimleri, 8(3), 721-750.

Aral N. ve Sağlam, M. (2012). Ebeveynleri boşanma sürecinde olan çocuklar ile ebeveynleri ile birlikte yaşayan çocukların duygularının cinsiyete göre incelenmesi. Ankara Sağhk Bilimleri Dergisi, 1(2), 71-88.

Arıkan, C. (1996). Halkem bosanmaya ilişkin tutumlar. Ankara: Başbakanlık Aile Araştırma Kurumu Yayınları.

Aypay, A. ve Eryılmaz A. (2011). Lise öğrencilerinin öznel iyi oluşları ve okul tükenmişliği arasındaki ilişkiler. International Online Journal of Educational Sciences, 3(1), 181-199.

Boyd, R. C. (2014). Sibling relationship quality, personality, and happiness (Doctoral dissertation, Northern Arizona University).

Boydak, M. ve Yüksel, Y. (2003). Öğrencilerin sınav kaygılarının öğrenmeleri üzerindeki etkileri. Doğu Anadolu Bölgesi Arastrmalar, 3(2003), 64-70.

Büyükdüvenci, S. (1993). Aristoteles'te mutluluk kavramı. Felsefe Dünyası, 9: 41-45.

Çivitçi, A. (2009). İlköğretim öğrencilerinde yaşam doyumu: Bazı kişisel ve ailesel özelliklerin rolü. Uludă̆ Üniversitesi Eğitim Fakïltesi Dergisi, 22(1), 29-52.

Erdoğdu, M. Y. (2007). Ana-baba tutumları ve öğretmen davranışları ile öğrencilerin akademik başarıları arasındaki ilişkiler. SAÜ Eg̈itim Fakültesi Dergisi, (14), 33 - 46.

Eryllmaz, A. (2009). Ergen öznel iyi oluş ölçeğinin geliştirilmesi. Türk Eğitim Bilimleri Dergisi, 7(4), 975-989.

Eryılmaz, A. (2010). Aile yapiss ergeni mutlu eder mi? Aile ve Toplum Dergisi, 6(2), 22-31.

Hacıfazlıŏlu, Ö., Karaırmak, Ö. ve Öztabak, M. (2012). Göç olgusu bağlamında lise öğrencilerinin aile profilleri ve akademik başarı durumları. Hasan Ali Yücel Eg̈itim Fakültesi Dergissi, 12(2), 81-97.

Joronen, K. ve Åstedt-Kurki, P. (2005). Familial contribution to adolescent subjective well-being. International Journal of Nursing Practice, 11(3), 125-133.

Karaaslan, G. (2010). Orta ögretim kurumlarnda ögrenci basarssm etkileyen faktörlerin istatistiksel analizi. İTÜ Fen Bilimleri Enstitüsü Yayımlanmamış Yüksek Lisans Tezi, İstanbul.

Karasar, N. (2007). Bilimsel araştırma yöntemleri (17. baskı). Ankara: Nobel Yaynnchllk.

Keskin, G. ve Sezgin, B. (2009). Bir grup ergende akademik başarı durumuna etki eden etmenlerin belirlenmesi. Frrat Sağhk Hizmetleri Dergisi, 4(10), 3-18.

Oskay, G. (1986). Değer yargılarından kaynaklanan ana-baba ergen çatışmasının sosyo ekonomik ve benzeri değişkenler açısından incelenmesi. Hacettepe Üniversitesi Eğitim Fakültesi Dergisi, 1, 222-244. 
Özen, Y. (2010). Kişisel sorumluluk bağlamında öznel ve psikolojik iyi oluş (sosyal psikolojik bir değerlendirme). Dicle Üniversitesi Sosyal Bilimler Enstitüsü Elektronik Dergisi, 4, 46-58.

Samurçay, N. (1982). Cocuklarda kardeș iliş̧kileri. Eğitim ve Bilim Dergisi, 6(36), 6-14.

Saral, S. (1993). Özel Trabzon Ata Koleji ögrencilerinin uyum düzeyleri ile akademik başarları arasindaki ilişkinin araștırlması. Yayınlanmamış Yüksek Lisans Tezi, Karadeniz Teknik Üniversitesi, Trabzon.

Sar1, M., Ötünç, E. ve Erceylan, H. (2007). Liselerde okul yaşam kalitesi: Adana ili örneği. Kuram ve Uygulamada Eğitim Yönetimi Dergisi, 13(2), 297-320.

Sarıcaoğlu, H. (2011). Üniversite ögrencilerinin psikolojik iyi olma düzeylerinin kişilik özellikleri ve öz-anlayıs açısından incelenmesi. . Yayınlanmamış Doktora Tezi, Selçuk Üniversitesi Eğitim Bilimleri Enstitüsü, Konya.

Şentürk, Ü. (2008). Modern kontrol: tüketim. C.Ü. Sosyal Bilimler Dergisi, 32(2), 221-239.

Tanhan, F. (2007). Ölüm kaygısı ile baş etme eğitiminin ölüm kaygısı ve psikolojik iyi olma düzeyine etkisi. Yaynlanmamıs Doktora Tezi), Ankara Üniversitesi Eğitim Bilimleri Enstitüsü, Rebberlik ve Psikolojik Danısma Bölümü, Ankara.

Tatlıŏ̆lu, K. (2012). Üniversite öğrencilerinin kardeş sayıları ile psikolojik iyi oluşları arasındaki ilişkinin incelenmesi. Turkish Studies, 7(4), 2857-2872.

Topses, M. D. (2013). Eğitim düzeyi ve kardeş sayısının suç davranışıyla ilişkisisi: Çanakkale E tipi kapalı ceza infaz kurumu örneği. International Journal of Social Science, 6(3), 701-713

Tuncer, Ö., Atay, M., Türker, Y. ve Tuncer, H. (2014). Adolesanlarda Kardeş Sayısı ile Öz-Kavram İlişkisi. Düzce Tip Fakültesi Dergisi, 16(3), 22-25.

Ünüvar, P., Çalışandemir, F., Tagay Ö. ve Amini, F. (2015). Okul öncesi dönem çocuklarının mutluluk algisı (Türkiye ve Afganistan örneği). Mehmet Akif Ersoy Üniversitesi Ĕ̈itim Fakültesi Dergisi, 1(34), 1-22.

Yılmaz, E., Yiğit, R. ve Kaşarc1, İ. (2012). İlköğretim öğrencilerinin özyeterlilik düzeylerinin akademik başarı ve bazı değişkenler açısından incelenmesi. Mehmet Akif Ersoy Üniversitesi Eğitim Fakültesi Dergisi, 1(23), 371-388.

\section{EXTENDED ABSTRACT}

Happiness has been the topic of curiosity for a long time. The definition of happiness and how to reach happiness have been questioned since ancient times. The ways in which happy people interpret, evaluate and react to life events differ from those who are less happy (Unuvar et al., 2015, p. 2). Research shows that psychological disturbances are less common in happy people (Lu, 1995; Lyubomirsky, King, \& Diener, 2005; Unuvar et al., 2015, p. 2). While sincere, safe and supportive environments increase happiness and self-confidence in individuals, they can decrease the tendency to psychological problems (Unuvar et al., 2015:2). To buy what we want and to make consumption can be an important source of happiness today (Şentürk, 2008:231). However, this happiness may not be sufficient to ensure continuous hap-piness in the individual. Spiritual feelings can come to the fore in the continuity of happiness. At this point, social life areas of the people are of great importance. It is stated that social communication and interaction level are at the basis of happiness. The most basic interaction and communication areas of the people are their families. The level of family communication is especially important in adolescents (Aypay ve Eryllmaz, 2011, p. 193). In addition, some important developmental tasks must be fulfilled in order to achieve adolescence successfully. These are emotional independence from parents and other adults, social responsibilities and desiring to take part in these responsibilities (Sar1 et al., 2007, p. 298).

According to the literature research results, family relations have an effect on the happiness of the youth. While families with many children may have enough interest in their children, families with one child can provide a spoiled and non-regulated living environment for their children. No exact relationship was found between the number of siblings and happiness in these researches. In this study, the answer to the question of "Is psychological happiness of high school students different according to their siblings' characteristics?" was sought.

In this study, the differentiation status of happiness levels according to the sibling status of high school students (number, gender, age status of siblings) was investigated. The Qualitative Descriptive method was used in the research. The method of screening is a research method which aims to identify what is in the past or is it still present. The study group of the study is composed of 489 students who are continuing their education in Çanakkale in a High school. Within the scope of the research, the Oxford Happiness Scale which was developed by Hills and Argyle and adapted to Turkish by Doğan and Sapmaz (2012) was applied. For the internal consistency of the scale, Cronbach alpha reliability coefficient was calculated as 0.76 for the whole scale. SPSS statistical program and descriptive statistical analysis methods were used to analyze the data.

As a result of this study, it was found that there was no significant difference between the happiness scores according to the number of siblings. This result is similar to the results obtained by Civitci (2009), Tatlioglu (2012) and Tuncer et al. (2014) corresponds to the results obtained. Participants with only one 
sibling were found to be the happiest student group. They are followed by participants having two siblings. There was a gradual decrease in the happiness scores of the students having 3 and above siblings. It was also found that there was a significant difference between the happiness scores according to the siblings' gender and siblings' age status. It was found out that girls are happier than boys according to gender. This result is similar with the research results of TUIK (2014), Boyd (2014), Civitci (2009) and Copur et al. (2015). Elder and younger participants than their other siblings stated that they were happier than the other participants. Samurcay $(1982$, p. 9) states that the youngest is happy about feeling small and weak and that they consider themselves privileged in the family due to this situation. It was found out that happiness scores did not show a significant difference according to whether the gender of the sibling itself was the same or different. However, there was a significant difference in happiness scores according to the gender of siblings. Participants having sisters were happier than the participants having both brothers and sisters, and having only brothers.

In light of the data obtained, the value given by the family to their children and the time they allocate is very important. For this reason, it is understood that it is more important for families to have the number of children they can afford and pay attention to.

a) Mother and father's attitudes and behaviors towards children can be studied from a different dimension in different research.

b) The effect of quality time spent on family and siblings with happiness on family and siblings can be examined. 